\title{
Recovery Kondisi Denyut Nadi dengan Joging dan Istirahat Dinamis
}

\section{Bagas Dwi Laksana', Surdiniaty Ugelta ${ }^{1}$, Jajat ${ }^{1,2}$}

${ }^{1}$ Program Studi Ilmu Keolahragaan, Universitas Pendidikan Indonesia

${ }^{2}$ Pendidikan Jasmani, Universitas Galuh

bagasdwilaksana@gmail.com

diusulkan Juni 2019; diterima September 2019; dipublikasikan Oktober 2019

\begin{abstract}
ABSTRAK
Tujuan dari penelitian yaitu untuk mengkaji perbedaan pengaruh recovery jogging dengan recovery dinamis terbadap pulih asal denyut nadi. Metode yang digunakan pada penelitian ini adalab kausal komparatif, dan teknik pengambilan data dengan pusposive sampeling. Sampel dibagi menjadi 2 tim jogging dengan recovery dinamis. Sampel berjumlah 10 orang dan terdiri dari 2 tim futsal laki - laki yang berusia 18 - 24 tahun. Instrumen untuk mengukur heart rate menggunakan polar Ft 7 . Tujuan alat heart rate monitor ( Hrm ) adalab untuk memonitor detak jantung sampel pada tes penelitian games futsal secara langsung, atau real time, menampilkan jumlab detak jantung per-menit secara langsung selama beraktivitas. Hasil pengolah data menunjukan tidak ada perbedaan recovery jogging dan istirahat dinamis terhadap pulih asal $(p>.05)$. Dilihat dari deskripsi data, recovery istirahat aktifjogging rata-rata 11.0 dan recovery istirahat aktif dinamis 31.20. Penulusuran lebih lanjut yang spesifik. dan sistematis diperlukan terutama dari sisi jumlah sampel. Disarankan agar dilakukan tes kebugaran Vo2 max lebih dabulu karena untuk. mengetahui kondisi fisik sampel penelitian.
\end{abstract}

Keywords: Recovery, denyut nadi, jogging, istirahat, dinamis.

\section{PENDAHULUAN}

Olahraga menurut (Giri Wiarto, 2013:163) adalah aktifitas sistem muskulo skeletal yang sistematis dan terstruktur dengan frekuensi, intensitas, type dan waktu yang telah ditentukan, dengan olahraga bisa mendapatkan kondisi tubuh yang sehat. Kelelahan sering terjadi pada saat latihan intensitas tinggi dan pada kompetisi yang menjalani pertandingan berulang-ulang dengan jeda waktu yang singkat satu hari atau kurang dari 24 jam, setelah menjalankan olahraga, kita harus melakukan pemulihan, Recovery aktif adalah suatu metode pemulihan yang mengacu pada kecepatan menghilangkan kadar asam laktat, aktivitas yang dilakukan secara umum berupa latihan aerobik ringan. Intensitas latihan aerobik selama recovery aktif tidak lebih dari $60 \%$ dari denyut nadi maksimal, aktivitas seperti jogging ringan akan menurunkan akumulasi asam laktat $62 \%$ dalam 10 menit pertama dan akan bertambah 26 $\%$ pada $10-20$ menit berikutnya.

Peregangan merupakan syarat mutlak bagi setiap permulaan aktifitas olahraga yang bertujuan untuk mencegah cedera atau robek otot. Pemanasan juga merupakan persiapan emosional, psikologis dan fisik untuk melakukan latihan (Brick, 2001). Penyebab 
terjadinya kelelahan pada atlet adalah akibat dari penumpukan asam laktat pada otot, seperti yang dikemukakan oleh (Dinagsit, 2009) "kelelahan timbul karena penumpukan asam laktat dalam jaringan. Hal ini disebabkan oleh kemampuan tubuh menetralisir tumpukan asam laktat tersebut tidak sebanding dengan kecepatan asam laktat yang terbentuk akibat beratnya aktivitas olahraga yang dilakukan. Jika berlangsung lama, keadaan ini akan sangat mengganggu performa seseorang."

Menurut Sharkey (2003) menyatakan bahwa "kapasitas aerobik adalah kapasitas untuk mengirup, menyalurkan dan menggunakan oksigen.' Salah satu tes pengukuran $\mathrm{VO}_{2} \mathrm{Max}$ yaitu Bleep test, menurut Iztok Kavcic1 dkk. (2012) menyatakan bahwa “The multi-stage 20-m shuttle run test (MSRT) is one of the most popular field test using equations based on test results or the final speed for an indirect estimation of maximal oxygen uptake (VO2Max)". Dari pernyataan di atas dapat disimpulkan bahwa multi-stage $20-\mathrm{m}$ shuttle run test atau disebut juga Bleep test merupakan salah satu tes lapangan yang populer digunakan untuk mencari nilai perkiraan $\mathrm{VO}_{2} \mathrm{Max}$. Data nilai $\mathrm{VO}_{2} \mathrm{Max}$ tersebut digunakan sebagai evaluasi bagi atlet, baik evaluasi dalam latihan maupun sebagai parameter ketercapaian latihan.

Sebelum terjadi reaksi aerobik, ketika memulai suatu latihan yang menjadi sumber energi adalah energi yang didapat dari reaksi anaerobik, yaitu reaksi yang tidak memerlukan suplai oksigen. Biasanya reaksi ini terjadi pada 2 menit awal melakukan latihan. Oleh karena kapasitas dari reaksi anaerobik ini terbatas, maka orang akan cepat merasa lelah. Ketika telah merasa lelah, barulah sistem aerobik akan berlangsung yang menghasilkan ATP untuk sumber energi dalam melanjutkan latihan tersebut. Sistem aerobik ini dapat menghasilkan kapasitas yang jauh lebih besar dibandingkan sistem anaerobik sehingga seseorang dapat melakukan latihan sampai beberapa jam lamanya (Hairy, 2003).

Daya tahan adalah kesanggupan jantung dan paru serta pembuluh darah untuk berfungsi secara optimal dalam keadaan istirahat serta latihan untuk mengambil oksigen kemudian mendistribusikannya ke jaringan yang aktif untuk digunakan pada pada proses metabolisme tubuh. Daya tahan ini sering disebut sebagai daya tahan aerobik (Stølen, Chamari, Castagna, \& Wisløff, 2005). Olahraga aerobik adalah setiap jenis kegiatan fisik yang dilakukan pada tingkat intensitas sedang untuk jangka waktu tertentu. Dalam sistem aerobik ini bahan bakar di-suplai baik dari karbohidrat maupun dari lemak yang tersimpan di dalam tubuh kita, dengan oksigen sebagai proses konversi (pengubah) energinya". Harsono (2016).

Menurut Sukadiyanto (2011) "Peningkatan VO2max menjadi lebih tinggi mulai umur 10 tahun, walau ada yang berpendapat latihan ketahanan tidak terpengaruh pada kemampuan aerobik sebelum usia 11 tahun. Secara umum, kemampuan aerobik turun perlahan setelah usia 25 tahun". 
Dalam melatih komponen daya tahan cooling down rutin menjadi penting, harus diperlukan waktu cukup lama untuk menjadi bagian yang integral dalam sesi- sesi memperoleh perkembangan yang optimal. latihan. Menurut (Harsono, 1988: 158) ada dua Namun dalam beberapa pertandingan sering kali selang waktu yang tersedia hanya sedikit. Sehingga diperlukan metode latihan yang efektif dan efesien yang bisa dipakai oleh atlet untuk bisa meningkatkan daya tahan dalam waktu yang tersedia. Metode latihan yang dapat dipakai untuk maksud tertentu adalah metode interval training dan metode continuous training.

Walaupun akumulasi laktat menjadi penyebab terjadinya kelelahan, akumulasi laktat juga dapat dikonversikan menjadi bahan bakar energi melalui proses difusi laktat dari otot menuju aliran darah. Laktat akan terakumulasi pada olahraga atau latihan yang memiliki karakteristik intensitas tinggi (Gur, 2015). Pada umumnya pemulihan yang sering kita lakukan setelah latihan atau pertandingan yaitu istrahat aktif jogging dan isitrahat aktif dinamis, karena mudah untuk melaksanakannya. Jogging sebagai kegiatan berlari lebih lambat atau lari kecil dari $6 \mathrm{mph}$ (10 menit per mil kecepatan), ada juga pengertian isitrahat aktif dinamis yaitu, gerakan yang mengulur otot dalam persendian sesistematis mungkin, kemudian mempertahankan posisi tersebut selama 20 sampai 30 detik, seperti dikemukakan oleh (Harsono, 1988 : 167). Salah satu penyebab lambatnya recovery adalah akumulasi asam laktat di dalam otot dan darah, tubuh kita memang mampu menerima adanya asam laktat dalam darah. Dalam hal ini prosedur recovery/ bentuk interval training yaitu interval training lambat akan tetapi dengan jarak lebih jauh lama latihan : 60 detik - 3 menit, intensitas latihan : 10\% - 70\% max, ulangan lari : $10-20$ kali, istirahat : $3-5$ menit, waktu terbaik $800 \mathrm{~m}: 2$ menit 20 detik. Interval training cepat akan tetapi dengan jarak yang lebih dekat, lama latihan: 5 - 30 menit, intensitas latihan : 85\% 90\% max, ulangan lari : $20-25$ kali, istirahat : 30 - 90 detik, waktu terbaik 100 m : 12 detik.

\section{METODE}

Metode penelitian yang digunakan dalam penelitian ini adalah metode causal comparative. Tujuan penelitian ini yaitu mengetahui apakah ada perbedaan signifikan antara pulih asal jogging dengan pulih asal dinamis terhadap kecepatan recovery permainan futsal.

\section{Prosedur}

Pelaksanaan sampel bersiap - siap diluar lapang futsal dan kelompok telah dibagi dalam menjadi dua kelompok, yaitu tim A dan tim B. Sampel menggunakan instrumen penelitian menggunakan tes Heart Rate Polar Ft 7, Heart Rate Monitor (HRM).

Langkah selanjutnya adalah pengambil data melakukan pengarahan tata cara pemakaian dan penilian jalannya penelitian, setelah itu sampel mengisi data yang yang telah disediakan oleh pengambil data diluar lapangan sebelum 
tes dilaksanakan setelah selesai bersiap untuk melakukan tes penelitian games futsal selama 20 x 2 menit (Asmar Jaya, $2008: 27$ - 30).

\section{Partisipan}

Penelitian ini akan dilakukan di Gor Sky Sport, Jl. Rancabolang No. 167 Buah Batu Kota Bandung, pada hari, 25 Juni 2018, pukul 19.00 - 20.00 WIB. Partisipan pada penelitian ini adalah anggota futsal tim Samoja Gnz Kota Bandung, yang berjenis kelamin laki - laki dan berusia 18 - 24 tahun, jumlah yang terlibat dalam penelitian ini adalah 10 orang, dilihat dari jumlah popluasi anggota futsal yaitu 25 anggota (Moore et al., 2012).

Instrumen

Pada penelitian ini menggunakan alat ukur tes bantu heart rate polar Ft 7. Tujuan alat heart rate monitor ( $\mathrm{Hrm}$ ) adalah untuk memonitor detak jantung seseorang secara langsung, atau real time, menampilkan jumlah detak jantung per menit secara langsung, selama beraktivitas jasmani, strap ini dipasang di dada, tepat di dekat jantung, dan alat ini juga dilengkapi dengan fitur penghitung kalori. Tujuan dari penelitian ini menggunakan alat ini untuk mengetahui dan mencatat hasil berapa kemampuan heart rate sampel tim A pulih asal jogging dan tim B pulih asal dinamis pada penelitian ini.

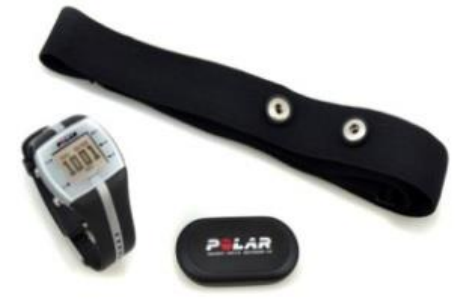

Gambar 1. Alat Polar Ft 7

\section{HASIL DAN PEMBAHASAN}

Penelitian ini dilakukan untuk mengetahui apakah ada perbedaan yang signifikan antara pulih asal jogging dan pulih asal dinamis terhadap recovery permainan futsal. Setelah data dikumpulkan maka di dapatikan hasil, sebagai berikut.

Table 1. Deskripsi Data

\begin{tabular}{lc}
\hline $\begin{array}{c}\text { Kelompok } \\
\text { Sampel }\end{array}$ & Mean \\
\hline Jogging & 11.0 \\
\hline Dinamis & 31.20 \\
\hline
\end{tabular}

Dari hasil perhitungan kelompok jogging memiliki mean sebesar 11,0 dan standar deviasi sebesar 22,011. Kemudian, dari hasil perhitungan dinamis memiliki nilai mean sebesar 31.20 dan mean 12,853.

Tabel 2. Hasil Uji Independent Sampel T-test

\begin{tabular}{cc}
\hline $\mathrm{t}$ & $\mathrm{p}$ \\
\hline$-1,772$ & 0,114 \\
\hline
\end{tabular}

Berdasarkan tabel diatas, $t$ yang diperoleh sebesar - 1, 772 sedangkan nilai sig (2 tailed) atau p value sebesar 0.144 di mana lebih besar dari nilai probabilitas $>0.05$. Karena $>$ 0.05 maka dengan demikian memeliki arti yaitu 
Ho diterima yang memiliki makna bahwa tidak ada perbedaan secara siginifikan antara variabel tim pulih asal jogging dan pulih asal dinamis pada probabilitas 0,05 .

Nilai hasil pengolahan data yaitu, pulih asal jogging 11.0 dan pulih asal dinamis 31.20. Penulusuran atau penelitian lebih lanjut yang spesifik dan sistematis harus diperlukan karena untuk akurasi hasil data penelitian. Disarankan agar dilakukan tes kebugaran $\mathrm{VO}_{2} \mathrm{Max}$ lebih dahulu karena untuk mengetahui kondisi fisik sampel penelitian. Dan hasil penelitian menunjukan bahwa tidak ada perbedaan hasil yang signifikan. Sesuai dengan penelitian sebelumnya yaitu bahwa recovery aktif lebih baik dibandingkan recovery pasif, Wells (dalam Valenzuela dkk, 2015). Penelitian yang dilakukan Monedero \& Donne (2010) menyatakan bahwa tidak terdapat perbedaan antara recovery pasif dengan masase akan tetapi kombinasi masase dengan pulih asal aktif lebih baik dibandingkan dengan masase.

Berdasarkan sebuah penelitian yang dilakukan oleh Barbero Alvarez, (2008). Ratarata heart rate pemain futsal ketika mengarungi sebuah kompetisisi adalah 174 bpm dan menempuh jarak sejauh $4313 \mathrm{~m}$ dalam satu pertandingan, dengan hasil itu dapat diketahui intensitas permainan futsal yang bisa digunakan dalam acuan pembuatan program latihan, harapannya penelitian-penelitian yang meneliti tentang olahraga beregu, meneliti olahraga tersebut sampai kepada posisi-posisi yang dimainkannya agar pengetahuan yang didapat juga lebih menyelutuh dan pada kenyataanya penelitian - penelitian yang ada hanya meneliti secara umun dan belum dilakukan penelitian sampai ke posisi - posisi yang dimainkan, pedahal perlu diteliti heart rate para pemain perposisi karna hasilnya nantinya akan menjadi bahan pertimbangan dalam pembuatan program latihan yang lebih spesifik terhadap para pemain. Dari hasil pengalaman dan observasi yang peneliti lakukan diberbagai club - club futsal dan juga diUnit Kegiatan Mahasiswa Futsal UPI, peneliti melihat tidak adanya spesialisasi latihan dalam olahraga futsal yang mengacu pada posisi yang di mainkan, padahal teori-teori atau sumber-sumber yang peneliti baca dan berdasarkan pengamatan peneliti melihat bahwa setiap posisi memiliki spesialisasi dan juga karakter yang beda. (Tokmakidis dkk., 2011) pada kompetisi yang menjalani pertandingan berulang-ulang dengan jeda waktu yang singkat (satu hari atau kurang dari 24 jam). Pada akhirnya, kelelahan akan menyebabkan penurunan performa. (Plowman \& Smith, 2011). Durasi aktif recovery selama 15 menit cukup untuk meeliminasi laktat dibandingkan dengan pasif recovery, seperti yang diungkapkan (Tokmakidis dkk, 2011). Kelelahan-kelelahan yang terjadi pada atlet tersebut harus diatasi, salah satu caranya dengan terapi yang menggunakan air sebagai medianya dikenal dengan nama Hydrotheraphy (Halson et al., 2014; Stanley, Buchheit, \& Peake, 2012; Vaile, Halson, Gill, \& Dawson, 2008). Penggunaan air baik dalam wujud cair, larutan, 
dan uap dalam terapi melawan penyakit, trauma dan massage (pijatan) dinamakan Hydromassage.

Penelitian ini dilakukan untuk mengetahui apakah ada perbedaan yang signifikan antara pulih asal jogging dan pulih asal dinamis terhadap recovery permaianan futsal. Hasil pengolahan data menyatakan bahwa tidak terdapat perbedaan yang signifikansi. Dari hasil perhitungan hasil uji deskriptif tim pulih asal jogging memiliki mean sebesar 11,0 dan standar deviasi sebesar 22,011. Kemudian, dari hasil perhitungan tim pulih asal dinamis memiliki nilai mean sebesar 31.20 dan mean 12,853. Dan berdasarkan hasil uji sampel independet $t$ test , nilai t yang diperoleh sebesar 1,772 sedangkan nilai sig ( 2 tailed) atau $p$ value sebesar 0.144 dimana lebih besar dari nilai probabilitas $>0.05$. Karena $>0.05$ maka dengan demikian memeliki arti yaitu Ho diterima yang memiliki makna bahwa tidak ada perbedaan secara siginifikan antara variabel tim pulih asal jogging dan pulih asal dinamis pada probabilitas 0,05 .

\section{KESIMPULAN}

Hasil dari penelitian ini menunjukan hasil bahwa tidak ada perbedaan data yang signifikansi antara kedua tim antara pulih asal jogging dan pulih asal dinamis.

\section{REFERENSI}

Afriwardi, 2008. Pengaruh Pemulihan Aktif Dan Pemulihan Pasif Terhadap Lamanya Perubahan Kadar Laktat Darah Pada
Mahasiswa
Fakultas
Kedokteran
Universitas
Andalas.
Majalah

Keodekteran Andalas. Vol 32. No. 2

Arikunto, Suharsimi. Prosedur Penelitian: Suatu Pendekatan Praktik. Jakarta; Rineka Cipata. 2006.

Bafirman. 2006. Fisiologi Olahraga. Buku Ajar Tidak Diterbitkan. Padang: FIK UNP.

Barbedo A. Granda J and Manuel V (2008). Match Analysis and Heart Rate Of Futsal Palyers During Competition.

Brick, L. (2001). Bugar Dengan Senam Aerobik. Jakarta:PT. Raja Grafindo Persada.

Dangsina Moeloek, (1984). Kesehatan dan Olahraga. Jakarta: Fakultas Kedokteran Universitas Indonesia.

Depdikbud, (1995). Tes Kesegaran Jasmani Indonesia. Jakarta: Pusat Kesegaran Jasmani.

Dinagsit, D. (2009). Perbedaan Pengaruh Metode Massage Air (Hydromassage) Dan Metode Massage Manual Terhadap Performa Setelah Kelelahan. Universitas Pendidikan Indonesia.

Ervana, A. 2010. Efektifitas Pemberian ATP dari Luar Terhadap Pemulihan Kelelahan Otot Gastrocnemius Rana SP, Bogor: FKH IPB.

Fox, L E., Bower, R., and Foss,M,: 1988, The Physiology Basis of Physical Education and Athletics; New York: Sunders College Publishing. Guyton, A.C.; 1991. Fisiologi Kedokteran; (terjemahan); Jakarta: EGC 
Giriwijoyo, S dan Zafar Sidik, D. (2012) Ilmu Kesehatan Olahraga. Bandung Fakultas Pendidikan Olahraga dan kesehatan Universitas Pendidikan Indonesia.

Giriwijoyo, Santosa dan Dikdik Zafar Sidik.

2012. Ilmu Kesehatan Olahraga Bandung: Rosda.

Gur, E. (2012. A Comprison Of Blood Lactate Level And Heart Rate Following A Peak Anaerobic Power Test In Dufferent Exercise Loads. European Journal of Expreimental Biology, 1854-1861.

Guyton. 1994. Fisiologi Manusia dan Mekanisme Penyakit. Edisi ke 7. Jakarta: EGC. Hal. 149 - 166, 202 - 204.

Hairy, J (2003). Daya Tahan Aerobik. Jakarta: Direktorat Jenderal Olahraga

Departemen Pendidikan Indonesia.

Halson, S.L., Bartram, J., West, N., Stephens, J., Argus, C. K., Driller, M. W Martin, D T. (2014). Does Hydrotherapy Help Or Hinder Adaptation To Training In Competitive Cyclists. Med Sci Sports Exerc, 46 (8), 1631-1639.

Harsono 1988, Coaching dan Apek-aspek Psikologis dalam coaching. C.V. Tambak Kusuma, Jakarta.

Harsono, (2016). Latihan Kondisi Fisik (Untuk Atlet Dan Kesehatan). Bandung. FPOKUPI Bandung.

Hartono, widiyanto, Suprijanto. 2012. Perubahan Kadar Asam Laktat Darah dan Performa Anaerobik Setelah recovery
Oksigen dan recovery Aktif. Jurnal IPTEK Olahraga. Vol. 14. No. 2.

Hasyim Efendi (1983). Fisiologi Kerja dan Olahraga serta Peranan Tes Kerja (Exercise Test) untuk Diagnostik. Bandung: Penerbit Alumni. Hlm 59-121. Hernawati. Produksi Asam Laktat Pada Exercise Aerobik dan Anaerobik. FMIPA, Universitas Pendidikan Indonesia.

Imanudin, I. (2014). Tabel Skala Intensitas Berdasarkan Denyut Nadi Bahan Ajar Ilmu Kepelatihan Olahraga. Bandung: Universitas Pendidikan Indonesia.

Imanudin, Iman. (2008). Ilmu Kepelatihan Olahraga. Bandung: Universitas Pendidikan Indonesia.

Iztok Kavacic Dkk, (2012). Comparative Stufy of Measured and Predicted Vo2max During A Multi-Stage Fitness Test With Junior Soccer Players. Comparative Study Of Measured And Predicted. Kinesiology (2012).

Junusul Hairy. 1989. Fisiologi Olahraga.Jakarta:

Depdikbud. Dirjendikti.

Kasiyo Dwijowinoto (1993). Dasar-dasar Ilmiah Kepelatihan. Semarang: IKIP Semarang Press.

M. Anwari Irawan. 2007. Glukosa \& Metabolisme Energi. Polton Sport Scince\&Performance Lab. Vol 06. http://www.pssplab/journal/06.pdf. Menzies, P., Menzies, C., Mcintyre, L., Paterson, P., Wilson, J., \& ole, K.J. (2010). 
Blood Lactate Clearance During Active Recovery After An Intense Running Bout Depends On The Intensity Of The Active Recovery. Journal of Sport Science, 975-982.

M. Sajoto, 1996, Peningkatan dan Pembinaan Kekuatan Kondisi Fisik dalam Olahraga, Semarang, Dahara Prize.

Mondero, J., \& Donne, B. (2000). Effectof Recovery Interventions on Lactate Removal and Subsuequent Performance. Internasional Journal of Sport Science 593-597.

Nurhasan. (2013). Tes dan Pengukuran Dalam Pendidikan Jasmani. Bandung STKIP.

Plowman, S. A., \& Smith, D. L (2011). Exercise Physiology For Heath, Fitness, And Performance, Philadhelphia: Lippincott William \& Wilkins.

Pyke dalam Sukadiyanto dan Muluk, (2011: 80)

Tabel Metode Latihan Daya Tahan dan Sasaranya.

Sukadiyanto, (2011). Pengantar Teori Dan Metodologi Melatih Fisik. Bandung Lubuk Agung.

Suniar, Leaene. (2002). Dukungan Zat-Zat Gizi Untuk Menunjang Prestasi Olahraga. Jakarta: Kalamedia.

Supariasa, I.D.N. dkk. 2013. Penilaian Status Gizi (Edisi Revisi). Jakarta: Penerbit Buku Kedokteran EGC.

Soekarman, (1998). Peningkatan dan Pembinaan Kondisi Fisik. Semarang: IKIP Semarang.
Soekarman, "Dasar Olahraga untuk Pembina, pelatih dan Atlet,"Jakarta: KPT Inti Idayu Press, 1987.

Stolen, T., Chamari, K., Castagna, C., \& Wisloff, U. (2005). Phyiology of Soccer sports medicine $25 \quad$ (6), 501-536. Htttps://doi.org/10.2165/00007256200535060-00004.

Tambayong, Jan. 2001. Anatomi Fisiologi untuk Keperawatan. Jakarta: Rineka Cipta.

Tokmakidis, S.P., Toubekis, A. T., \& Smilios, I. (2011). Active Versus Passive Recovery: Metabolic Limitatitons And Performance Out Come. In M. A. Powell, Physical Fitness Training, Effect and Maintraining (Pp. 1-43). New York: Nova Science Publisher.

Valenzila, P. L., Vila, d. P., \& Ferragut, C. (2015). Effect of Two Types of Active Recovery on Fatigue and Climbing Performance. Journal of Sport Science and Medicine, 769-775.

Wiarto, Giri (2013). Fisiologi dan Olahraga. Yogyakarta: Graha Ilmu.

Widiyanto, 2007. Latihan Fisik dan Laktat. Jurnal Midikora FIK UNY. 